\title{
The Application of Physiology Rules in P.E. Research Based on DEA Model of Secondary Relative Evaluation in Operational Research
}

\author{
Quan He \\ Department of physical Education, Nanchang Institute of Technology, Nanchang, Jiangxi
}

Keywords: operations research, secondary relative evaluation, physiology rule, cp consumption, dea model, motion frequency

\begin{abstract}
This paper researches the sports teaching psychology law based on the operational research secondary relative evaluation theory. It establishes secondary relative evaluation DEA model based on the reaction time, instantaneous velocity and body $\mathrm{CP}$ consumption in the - meter race. It analyzes the physical laws reflected in the sports activity regulation and movement intensity. It arranges the sports curriculum and movement frequency in physical activity according to the physical law of every student shows in sports activities process which including action control, body function strength and action of memory. It puts forward some PE teaching opinions and suggestions according to the physiology rule of sports teaching process which provide theoretical basis for sports teaching process in physiology rule research.
\end{abstract}

\section{Introduction}

In the process of sports, with the changes of physiology, the sports body physiological change of each stage is different. According to the movement task of each stage, we can really realize the function of sports. This paper first introduces the secondary relative evaluation model and establishes the physiological change rule model of physical strength and movement memory in the sports teaching process using DEA model theory[1]. It analyzes the time and instantaneous velocity of each stage in 100-metre race through the model. It finally finds that the physiological change law of athletes in 100-meters race in each phase is different. In the basis of this theory, this paper puts forward the objectives and tasks in the process of physical education. It gives relevant teaching recommendations for sports teaching and provides a theoretical reference for sports teaching.

\section{Secondary relative evaluation DEA model and FAHP evaluation method}

Relative evaluation DEA model is proposed by the operations research expert Charnes. He established C2R model, the model of the influence of input to output under various factors and accounted evaluation coefficient by the way of weighted[2]. Based on the theory, we can research the influence of activity, physical strength and movement memory on physical education and sports physiology. We can set research activity, physical strength and movement memory for input which are reported as A1, A2, A3 and set sports teaching B1 and sports physiology rule B2 for output. Because the input indicators and output indicators are not consistent we should input/output index using comprehensive weighted method. Action, physical strength and movement memory physiological regular indexes are shown in Table 1.

TABLE I. THE PHYSICAL LAW INFLUENCE TABLE IN SPORTS TEACHING

\begin{tabular}{|l|l|l|l|}
\hline Index & Action & physical strength & movement memory \\
\hline $\boldsymbol{A 1}$ & 5 & 9 & 2 \\
\hline $\boldsymbol{A 2}$ & 4 & 8 & 12 \\
\hline $\boldsymbol{A 3}$ & 5 & 3 & 7 \\
\hline $\boldsymbol{B} 1$ & 32 & 43 & 22 \\
\hline B2 & 15 & 7 & 9 \\
\hline
\end{tabular}


As shown in Table 1, for the influence of activity on the physical law, we can set output comprehensive value is $32 \mathrm{~b} 1+15 \mathrm{~b} 2$ and input comprehensive value is $5 \mathrm{a} 1+4 \mathrm{a} 25 \mathrm{a} 3$. b1 $\mathrm{b} 2$ 、a1 、 a2 $、$ a 3 are the weight coefficient of output and input.

Assuming that the influence efficiency of the activity on physical law which is the ratio of total input and total output is:

$$
k_{1}=\frac{32 b_{1}+15 b_{2}}{5 a_{1}+4 a_{2}+5 a_{3} !}
$$

We can know the effects efficiency of physical strength and movement memory are:

$$
k_{1}=\frac{43 b_{1}+7 b_{2}}{9 a_{1}+8 a_{2}+3 a_{3}} . \quad k_{1}=\frac{22 b_{1}+9 b_{2}}{2 a_{1}+12 a_{2}+5 a_{3}}
$$

We can get it after linear programming:

$$
\begin{gathered}
k_{1}=\frac{32 b_{1}+15 b_{2}}{5 a_{1}+4 a_{2}+5 a_{3}} \leq 1 . \\
k_{1}=\frac{22 b_{1}+9 b_{2}}{2 a_{1}+12 a_{2}+5 a_{3}} \leq 1 .
\end{gathered}
$$

Assuming that $\mathrm{m}=\frac{1}{5 a_{1}+4 a_{2}+5 a_{3}}$ and $\mathrm{xi}=$ nai, $\mathrm{yi}=\mathrm{nbi}$. So, we can transfer the fractional programming into linear programming which is listed below:

$$
\begin{aligned}
& \max k_{1}=32 b_{1}+15 b_{2} \\
& \text { s.t. }\left\{\begin{array}{l}
32 b_{1}+15 b_{2} \leq 5 a_{1}+4 a_{2}+5 a_{3} \\
43 b_{1}+76 b_{2} \leq 9 a_{1}+8 a_{2}+3 a_{3} \\
22 b_{1}+9 b_{2} \leq 2 a_{1}+12 a_{2}+5 a_{3} \\
5 y_{1}+4 y_{2}+5 y_{3}=1
\end{array}\right.
\end{aligned}
$$

The dual problem is:

$$
\begin{aligned}
& \min X_{a}=\partial \\
& \text { s.t. }\left\{\begin{array}{l}
5 \lambda_{1}+4 \lambda_{2}+5 \lambda_{3} \leq 5 \partial \\
9 \lambda_{1}+8 \lambda_{2}+3 \lambda_{3} \leq 15 \partial \\
2 \lambda_{1}+12 \lambda_{2}+5 \lambda_{3} \leq 8 \partial \\
32 \lambda_{1}+43 \lambda_{2}+22 \lambda_{3} \geq 32 \\
15 \lambda_{1}+7 \lambda_{2}+9 \lambda_{3} \geq 15
\end{array}\right.
\end{aligned}
$$

Assuming that Di is the weight of Gi which is the $\mathrm{i}$-th index. The input index weight is:

$$
\sum_{i=1}^{3} \mathrm{D} \mathrm{G}_{i j}
$$

Assuming that $\mathrm{Si}$ is the weight of $\mathrm{Zi}$ which is the $\mathrm{i}$-th index. The output index weight is:

$$
\sum_{i=1}^{3} \mathrm{~s}_{\mathrm{ir}} \boldsymbol{. 1}_{1}
$$

Affect efficiency can be defined as:

$$
k_{j}=\frac{\sum_{r=1}^{2} S_{i} Z_{i j}}{\sum_{i=1}^{n} D_{i} G_{i j}} 11
$$


Through such a series of transformation, we can get the consistency weight coefficient of action, physical strength and movement memory influence efficiency and then further study sports education in physical laws.

FAHP model belongs to the fuzzy evaluation class evaluation, assuming that the fuzzy judgment

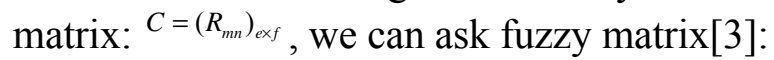

$$
C=\left(R_{m n}\right)_{e \times f} R_{m n}=\frac{1}{2 n} \sum_{x=1}^{n}\left(T_{e x}-T_{f x}\right) .
$$

FAHP model first do a secondary index evaluation, and finally combine each secondary index through the survey data, and get the ultimate evaluation results in the processing of data.

Secondary relative evaluation model of sports education physiology rule

Through the above description, we can get the weight coefficient of action, physical strength and movement memory which influenced sports education. Through the establishment of the DEA model, we can analyze the physical law of sports education[4]. The research object of this paper mainly is the physiological phenomena and laws of excellent athletes in the process of 100 meters. It analyzes the energy change of each stage of game process and forecasts the physiology phenomenon change rule in the process of sport.

The physiological change rule of athletes in the process of 100-meter race

First of all, we can study physiology change rule in the process of sports through the CP consumption of athletes in each stage. We can take instantaneous velocity and section time of ten meters far away from starting point and the analysis list is shown in Table 2 and Table 3.

TABLE II. SECTION SCHEDULE OF ATHLETES IN 100 METERS

\begin{tabular}{|l|l|l|l|l|l|}
\hline athletes & performance & Reaction(ms) & $\mathbf{1 0 m}$ & $\mathbf{3 0 m}$ & $\mathbf{6 0 m}$ \\
\hline One & 9.91 & 0.123 & 0.89 & 0.92 & 0.87 \\
\hline Two & 9.95 & 0.135 & 0.87 & 0.94 & 0.82 \\
\hline Three & 10.01 & 0.148 & 0.95 & 0.93 & 0.94 \\
\hline Four & 11.2 & 0.139 & 0.92 & 0.97 & 0.92 \\
\hline
\end{tabular}

TABLE III. INSTANTANEOUS SPEED TABLE OF ATHLETES IN 100-METRE

\begin{tabular}{|l|l|l|l|l|l|}
\hline athletes & $\mathbf{1 0 m}$ & $\mathbf{3 0 m}$ & $\mathbf{6 0 m}$ & $\mathbf{9 0 m}$ & $\mathbf{1 0 0} \mathbf{m}$ \\
\hline One & 8.75 & 10.05 & 11.25 & 11.85 & 11.25 \\
\hline Two & 8.86 & 10.12 & 11.13 & 11.26 & 11.36 \\
\hline Three & 8.91 & 10.52 & 11.02 & 11.98 & 11.52 \\
\hline Four & 8.95 & 10.86 & 11.68 & 12.01 & 11.38 \\
\hline
\end{tabular}

From Table 2 and Table 3 we can see that the time and instantaneous speed of athletes at every stage are different. Good athletes spend less time at each stage and the instantaneous velocity is faster. Bad athletes spend long time and its instantaneous speed is slower. It is related with personal physiological factor.

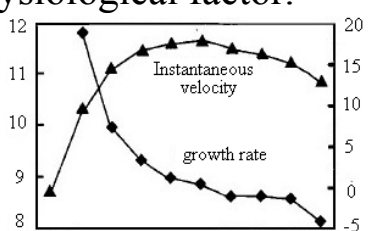

Figure 1. Instantaneous growth rate and growth rate

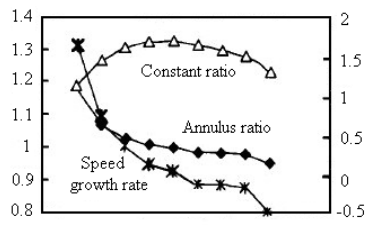

Figure 2. Instantaneous speed growth rate and constant ratio annulus ratio

From Figure 1 and Figure 2 we can see that the change of instantaneous speed is raised with curve first then decreases with curve and the growth rate is decreases with curve. In Figure 2 the constant ratio is rising curve, the speed growth rate and annulus rate are falling. 


\section{Reasonable sports education objectives and tasks through the physiology rule}

Through the above analysis we can find that memory physiological rule of action reaction, sports strength and action in every stage and every moment sports is different. So, we should consider different body physiological function of each student when making sports teaching objectives and tasks and formulate the class assignments which can adapt to the students. We should give theoretical guidance to students before the course and monitor each student's physiology in the process of class which can realize the purpose of sports exercise.

The aim of sports is to promote human health, and it is also a reasonable and effective way to promote a person's mental health[5]. When people in sports they put great importance to accelerate the physiological dynamic and the emphasis is also increasingly concerned about. This paper discusses the construction of sport physiological dynamic coupling model, and verifies the actual reliability of the physiological changes in the coupled model fitting movement, so not only can be more perfect model, but also can strengthen people's the ability to predict and explain the application of physiological changes in the exercise.

For the coupling model sports, the human heart, blood flow and pulse affect the role of the physiological dynamic of the people, and they are the basis to establish the coupling relations and sense of optimizing the coupled model, which is in line with the reality of the body's physiological the actual situation. It allows people to have a better understanding of the sport, and to know how they affect the physiological dynamic, what kind of relationship, how to undertake more effective physical exercise in order to better maintain a more healthy and a good mental state, but also helps people effectively improve and promote their physical activity, and their physical and physiological qualities.

Opinions and suggestions of physiology in sports education process

The first investigation and study, according to the company's securities and financial statements, the data acquisition, and then use the type of data processing[6].

$$
\mu_{\mathrm{ij}}^{\prime}=\frac{\mu_{\mathrm{ij}}-\bar{\mu}_{\mathrm{j}}}{\sigma_{\mathrm{j}}} \text {. }
$$

$\bar{\mu}_{\mathrm{j}}$ is the average of the survey, ${ }{ }_{\mathrm{j}}$ is the standard deviation of investigation.

We will introduce the secondary relative evaluation calculation process below, first we suppose the two vector $\mathrm{H}$ and $\mathrm{K}, \mathrm{H}$ represent the relative efficiency vector, $\mathrm{K}$ on behalf of the weight vector[7].

$$
\mathrm{H}=\left[\begin{array}{l}
\mathrm{H}_{11} \mathrm{H}_{12} \cdots \mathrm{H}_{1 \mathrm{in}} \\
\mathrm{H}_{21} \mathrm{H}_{22} \cdots \mathrm{H}_{2 \mathrm{i}}
\end{array}\right] . \quad \mathrm{K}=\left[\begin{array}{l}
\mathrm{K}_{11} \mathrm{~K}_{12} \cdots \mathrm{K}_{1 \mathrm{j}} \\
\mathrm{K}_{21} \mathrm{~K}_{22} \cdots \mathrm{K}_{21}
\end{array}\right] .
$$

For the relative weight coefficient of input/output:

$$
\mathrm{Hm}=\left[\begin{array}{cc}
1 & \mathrm{H}_{\mathrm{Im}} / \mathrm{H}_{2 \mathrm{~m}} \\
\mathrm{H}_{2 \mathrm{~m}} / \mathrm{H}_{\mathrm{Im}} & 1
\end{array}\right]
$$

Assume that judgment matrix $\mathrm{Hm}=(\mathrm{hij}) \mathrm{m}, \mathrm{Km}=(\mathrm{kij}) \mathrm{m}$, the judgment matrix is:

$$
\text { . . } \prod_{m=1}^{n}\left(h_{i j}\right)_{n}^{\frac{1}{n}} \text {. }
$$

Through the calculation, China's big three airlines data are as follows: 
Scores of three big airlines

\begin{tabular}{|l|c|c|c|c|}
\hline Colleges & 10 year & 10 year & 11 year & 11 year \\
\hline & $\begin{array}{c}\text { scores of } \boldsymbol{A} \\
\text { model }\end{array}$ & $\begin{array}{c}\text { scores of } \boldsymbol{F} \\
\text { model }\end{array}$ & $\begin{array}{c}\text { scores of } \boldsymbol{A} \\
\text { model }\end{array}$ & $\begin{array}{c}\text { scores of } \boldsymbol{F} \\
\text { model }\end{array}$ \\
\hline $\boldsymbol{X}$ & 0.2055 & 0.1238 & -0.2345 & 0.1257 \\
\hline $\boldsymbol{Z}$ & 0.06578 & 0.1098 & 0.1269 & 0.2376 \\
\hline $\mathbf{Z}$ & 0.1798 & -0.0536 & 0.2732 & 0.1056 \\
\hline
\end{tabular}

Using the secondary evaluation method of evaluation to get relative vector and weight as Table 5.

TABLE IV.

THREE RELATIVE SIZE AND WEIGHT

\begin{tabular}{|l|c|c|c|c|c|c|c|}
\hline College & Hm1 & Km1 & Hm2 & Km2 & Hm1/Km1 & Hm2/Km2 & q \\
\hline $\boldsymbol{X}$ & 0.69 & 0.52 & 0.31 & 0.25 & 0.98 & 1.25 & 0.8 \\
\hline $\boldsymbol{Y}$ & 1.31 & 0.99 & 0.61 & 0.45 & 0.89 & 1.36 & 0.9 \\
\hline $\boldsymbol{Z}$ & 0.67 & 0.51 & 0.29 & 0.32 & 0.87 & 1.29 & 0.8 \\
\hline
\end{tabular}

Table 5 gets the relative ratio and weight coefficient in the $\mathrm{C} 2 \mathrm{R}$ model which based on the calculation, $\mathrm{Hm} 1 / \mathrm{Km} 1$ is input weight indicator ratio, $\mathrm{Hm} 2 / \mathrm{Km} 2$ is output weight index, $\mathrm{q}$ is relative efficiency ratio for the big three airlines, from the Table we can see that the Internation relative efficiency ratio is highest, the relative efficiency ratio of south is smaller.

From the above analysis and Tables, we could get the following advices:

(1) Preparation before class and theoretical teaching

Before the sports course we should let the students to make full preparation. The first is the sports in small range which can make students realize the process from static to dynamic. Before the class we should teach physical education curriculum theory knowledge to students and let students understand the strength of the sports process and work out suitable activity plan in order to prevent fatigue and physiological loss result from the intense movement appeared in the process of sports.

(2) The right course tasks and goals

Physical education teachers should arrange the proper course task based on the students' body physiological rule. When making objectives determining appropriate range and distinguishing the different students, they should pay attention to each student.

(3) We can establish students' files of body and physiological

Physical education teachers should understand each student's physiology and establish students' physical files especially the patients with physical defects they should arrange proper sports activities for them in order to avoid physical damage result from intense sports activities and fatigue in the sports process.

\section{Research results analysis}

Based on this hypothesis, we stressed the emotional and cognitive goals of moving targets are undeniable, and to provide teachers in the training process, the possibility of the implementation, thus becoming the awareness-raising work.

There are often emotional contrasts; there is a cognitive, and on the basis of border between them is subtle but important, as pure emotion between functions of combination is impossible. Its main purpose is the basis of research achievements of the transformation from subject to help young teachers work of the object in the student on own initiative their training and development.

In the past, the training for the premise process is cognitive and emotional mechanism factors of their knowledge. The important thing is the particularity of their achievements, this change them, in a model (in this case in the special training plan) of existence, in other words, is involved in the study group characteristics. 
The sports teaching under the information technology, first, the teacher make teaching content programming, pass it to students through the information, which can use the multimedia teaching, and the construct information teaching system. The teacher not only teach theoretical knowledge of sports, but also can offer all sorts of problems, and through the information technology answer the corresponding question. At the same time, the assessment system conduct evaluation and diagnosis of students' learning effects, timely feedback the evaluation information to the students, the ports teaching process system model under the condition of information technology are shown as below.

From the perspective of empirical analysis, the information technology for physical training has a very good role in promoting, and information technology for physical training will have a more broad development space. This should cause everybody and the education circle of the extensive concern, however on the current college sports teachers in computer information technology level condition, it should strengthen the teachers' information technology application and the ability to upgrade, which can be better applied to teaching and effectively guide students' physical training. The future of sports competition is not only the skills competition, and more is the embodiment of a display of national comprehensive economic strength and the characteristics of high-tech information age, so the information technology will achieve sports promotion and realize sports take-off.

\section{Conclusion}

This paper first introduced the secondary relative evaluation DEA model, established physiology influence law evaluation model for action, physical strength and movement memory, analyzed the time and instantaneous velocity of athletes in each stage of 100- meters race using the method of mathematical statistics and finally found the physiological change laws of athletes in each phase of 100-meter race are different. So, it paid attention to the influence of physical rule changes on students in sports teaching process and gave the relevant opinions and suggestions. Physical education should strengthen the study of physiology rules. It should establish appropriate course objectives and tasks and evaluate the teaching character using a variety of evaluation methods. We should choice targets and tasks to adapt to the students which can causes the PE course achieve physical fitness goals and make great contributions to the development of sports.

\section{References}

[1] Long L.H., The Hausdorff dimension of fractals generated from representing system, Acta Mathematical Sinica Chinese series, Vol. 44, No. 4, 2009, pp. 627-632.

[2] C. Yang, China's civil aviation competition pattern and efficiency research, Contemporary finance, No. 12, 2010, pp. 6-15.

[3] Brain Tomson, The New one of China's Airprot Construction, Jane's Airport, No. 5, 2009, pp. $22-25$.

[4] M. Cao, B. Zhang, J. Luo, China's small and medium-sized insurance enterprise core competitiveness research based on DEA method, Xi'an university of electronic science and technology (social science edition), Vol. 5, No. 7, 2010 , pp. 174-178.

[5] A. Liu, Countermeasure research on current situation and development of Chinese university high level basketball team's coaches, Journal of Beijing Sport University, Vol. 8, No. 11, 2009, pp.12-15.

[6] Z. Song, Development countermeasures on university's high level sports team from the comparison of CUBA and NCAA, Journal of Shanghai Institute of Physical Education, No. 11, 2010, pp. 61-67.

[7] J. Zhang, S. Ge, F. Zhou, Studies on the Application of Computer Simulation in Basketball Shooting, AISS: Advances in Information Sciences and Service Sciences, Vol. 4, No. 10, 2012, pp. $278-285$. 